American Journal of Applied Sciences 9 (3): 440-445, 2012

ISSN 1546-9239

(C) 2012 Science Publications

\title{
Design and Simulation of a Soft Switched Dc Boost Converter for Switched Reluctance Motor
}

\author{
${ }^{1}$ Felix Joseph, X. and ${ }^{2}$ S. Pushpa Kumar \\ ${ }^{1}$ Department of EEE, PRIST University, \\ Noorul Islam University, Kumara Coil, India \\ ${ }^{2}$ Heera College of Engineering and Technology, \\ Nedumancaud, Kerala, India
}

\begin{abstract}
Problem statement: This study presents the design and simulation of a soft switched boost converter for a switched reluctance motor with a closed loop controller. A soft switching scheme is proposed in the converter with minimum components, which reduces the switching loss and stress across the switch so that the harmonic generation is reduced in the output. The switch used in this converter switched ON at zero current and switched OFF at zero voltage. Approach: Most of the research was done on the power converter circuit of the SRM to control the speed. But in the proposed system a soft switched boost converter was designed to regulate the input voltage to SRM for any line variations and a power converter is used to control the speed of SRM. The PI controller was used as closed loop controllers, which improves the speed control of the switched reluctance motor for any load and regulates the input voltage to SRM for any line variations. The duty cycle of the switch is controlled by PI controller using PWM technique. A 500W/50KHz PWM based soft switched boost converter was designed and simulated for $6 / 4$ pole 3 phase SRM with variable loads. The results were simulated using MATLAB SIMULINK. Results: The output of the soft switched dc converter gives a constant output voltage for any line variations, so that the input voltage to SRM is constant. The output speed of the SRM is controlled using PI controller and rotor current. Conclusion: The soft switched dc converter regulates the input supply and a power converter control the speed of Switched reluctance motor simultaneously.
\end{abstract}

Key words: Soft switched boost converter, zero voltage switching, zero current switching, switched reluctance motor, power converter, pi controller, non-linearity, input voltage, power density, stator poles, zero current, switched converter

\section{INTRODUCTION}

Switched Reluctance Motor Drives (SRD) are now become popular compared to conventional ac or dc motor drives due to their simple construction, robustness, high efficiency and high power density. However, in speed control this motor facing some problems due to its nonlinear characteristics. The function of flux linkage depending on phase current and rotor position represents the key characteristic of the Switched Reluctance Motors (SRM) and it is difficult to describe such a relationship due to the effects of magnetic saturation and double saliency of the construction. In order to improve its performance some advanced control strategies have been proposed, such as current or flux linkage profile control. To achieve these strategies the motor phase current or phase flux linkage should be controlled precisely. All these require increasing the switching frequency of converter to upgrade stability and dynamic response speed. On the other hand, the higher switching frequency may cause the higher switching losses, higher Electro-Magnetic Interference (EMI) and the lower overall efficiency.

The use of soft-switching techniques in converter can contribute to reduce them. A great deal researches and developments on SRM soft-switching converter have been reported. There are several converter methods available to regulate the power supply of SRM. The converters have different topologies (Lenin and Arumugam, 2011). These topologies are having number of switches according to the design (Maruthachalam and Palaniswamy, 2011). The SRM drives always have a phase winding in series with a switch. In case of a shoot through fault, the inductance of the winding limits the rate of rise in current and provides time to initiate protective relaying to isolate

Corresponding Author: Felix Joseph, X., Department of EEE, PRIST University, Noorul Islam University, Kumara Coil, India 
the faults. The phases of the SRM are independent and, in case of one winding failure, uninterrupted operation of the motor drive operation is possible. Many researchers presented studies on speed control of SRM using converters .In some studies soft switched based converters used to control the speed for SRM (Song et al., 2010). Some of the researchers presented neuro and fuzzy controller based converters (Kumar et al., 2006; Li and Yue, 2009; Mianhua. 2009).Some different converters were designed exclusively for SRM drives. A new converter for Switched Reluctance Motor (SRM) drive is discussed in a study (Reis et al., 2009), which uses one switch in each phase.

The proposed converter is suitable for high speed drive application which is mainly due to the fast phase current commutation capability of this converter and due to generation of negative torque consequently generation of large ripple torque in SRM drives are resolved. A study described a soft switching converter (Guanxu, et al., 2009) for switched reluctance motor to improve the performance of the drive. All these methods have some disadvantages in the switching operation without soft switching or speed control are not precise and they do not consider the load and line variations.

In this study we designed a soft switched boost converter in the dc link of the $6 / 4$ structure SRM to regulate the input supply and a power converter is designed to control the speed, for load changes and supply disturbances using two closed loop PI controllers. In these converters with closed loop control we achieve a constant speed and voltage for any load and line variations.

Switched reluctance motor: The Switched Reluctance Motor (SRM) drives for industrial applications are of recent origin. Key to an understanding of any machine is its torque expression, which is derived from first principles. The implications of machine operation and its salient features are inferred from the torque expression. The torque expression requires a relationship between machine flux linkages or inductance and the rotor position. The reluctance motor is a type of synchronous machine. It has wound field coils of a DC motor for its stator windings and has no coils or magnets on its rotor. Figure 1 shows its typical structure of $6 / 4$. It can be seen that the stator and rotor have salient poles; hence, the machine is a doubly salient machine. The rotor is aligned whenever the diametrically opposite stator poles are excited. In a magnetic circuit, the rotating part prefers to come to the minimum reluctance position at the instance of excitation. While two rotor poles are aligned to the two stator poles, another set of rotor poles is out of alignment with respect to a different set of stator poles.
Then, this set of stator poles is excited to bring the rotor poles into alignment.

Development of torque: The most general expression for the torque produced by one phase at any rotor position is Eq. 1:

Torque $\mathrm{T}=[\partial \mathrm{W} / \partial \Theta] \mathrm{i}=$ Constant

Since $\mathrm{W}^{`}=$ Co-energy $=1 / 2 \mathrm{~F} \Phi=1 / 2 \mathrm{~N}$ I $\Phi$

This Eq. 2 shows that input electrical power goes partly to increase the stored magnetic Energy $(1 / 2 \mathrm{~L} * \mathrm{i} 2)$ and partly to provide mechanical output power $\left(i^{\mathrm{s}} / 2 \times\right.$ $\mathrm{dL} / \mathrm{d} \Theta \times(\omega)$, the latter being associated with the rotational e.m.f. in the stator circuit.

Neglecting saturation non-linearity Eq. 3:

$\mathrm{L}=$ Inductance $=\mathrm{N} \Phi / \mathrm{I}$

$\mathrm{T}=1 / 2 \mathrm{i}^{2} \mathrm{dL} / \mathrm{d} \Theta$

This Eq. 4 shows that the developed torque independent of direction of current but only depends on magnitude of current and direction of $\mathrm{dL} / \mathrm{d} \Theta$.

\section{Generalized Equation of motor:}

$$
\begin{aligned}
& \mathrm{V}=\mathrm{ri}+\mathrm{d} \Psi / \mathrm{dt} \\
& \Psi=\mathrm{Li}=\mathrm{N} \varphi, \text { For } \mathrm{r}=0 \\
& \mathrm{~V}=\mathrm{Ldi} / \mathrm{dt}+\mathrm{i}(\mathrm{dL} / \mathrm{d} \theta)(\mathrm{d} \theta / \mathrm{dt})
\end{aligned}
$$

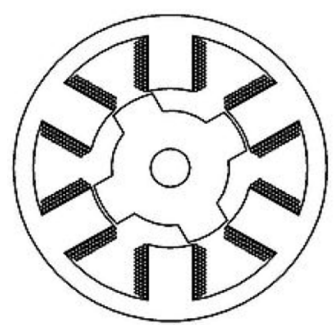

Fig. 1: SRM with $6 / 4$ poles

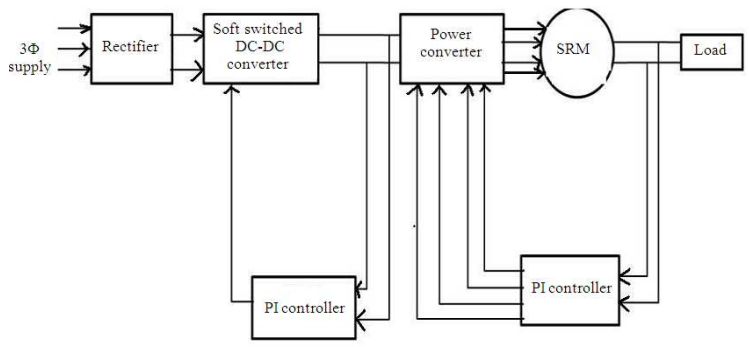

Fig. 2: Block diagram of the proposed converters and controllers for $6 / 4$ poles 3 phase SRM 


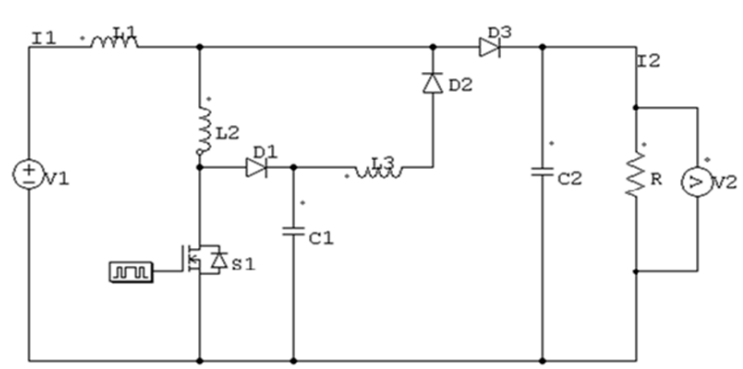

Fig. 3: Design and analysis of the proposed converter

$\mathrm{V}=\mathrm{L} d \mathrm{~d} / \mathrm{dt}+\mathrm{i} \omega(\mathrm{dL} / \mathrm{d} \theta)$

The Eq. 5-7 shows the input voltage to SRM mainly depends on voltage drop in the inductance and resistance.

The block diagram in Fig. 2 shows the proposed controller with two converters. The rectifier converts ac to dc and dc fed to the soft switched DC-DC converter, which regulates the voltage to the power converter with the help of the closed loop PI controller. The switch used in this converter switched $\mathrm{ON}$ at zero current and switched OFF at zero voltage. The regulated output for any line variations from the converter is given to the power converter. The power converter has four switches and all are used to control the speed of srm. The closed loop PI controller triggered the gate signals of these switches by the variable speed signals taken from the motor. The rotor position is sensed by sensor less control method. According to the rotor position and variable speed, PI controller sends triggering signal to the gate. This closed loop controller maintains the speed constant, which is set as reference. Thus the controllers used in these converters regulate the input supply and control the speed for any load and line variations.

Design and analysis of soft switched dc-dc boost converter: The configuration diagram of the proposed converter with soft switching scheme is shown in Fig. 3, the switch S1, L1, D3 and C2 are the main boost converter components, while $\mathrm{R}$ represents the resistive load on the converter. Inductor L2, L3, D1, D2 and C1 form the auxiliary circuit for accomplishing the soft switching of S1. Inductors L2 and L3 are much smaller than $\mathrm{L} 1$ and $\mathrm{C} 1$ is much smaller than $\mathrm{C} 2$. There are seven modes of operation.

Operational analysis of the proposed converter: Mode 1: This mode begins with the turn on of S1, at zero current at $0_{t}$. The expressions are Eq. 8-10:

$$
\begin{aligned}
& \mathrm{iL}_{2}(\mathrm{t})=\frac{\mathrm{V}_{1}}{\mathrm{~L}_{2}} \mathrm{t} \\
& \mathrm{V}_{\mathrm{Cl}}(\mathrm{t})=\left[\mathrm{V}_{1}-\mathrm{V}_{\mathrm{C}_{1}}\left(\mathrm{t}_{0}\right)\right]\left[1-\cos \omega_{1} \mathrm{t}\right]+\mathrm{V}_{\mathrm{C}_{1}}\left(\mathrm{t}_{0}\right) \\
& \mathrm{i}_{\mathrm{L}_{3}}(\mathrm{t})=\left[\mathrm{V}_{\mathrm{C}_{1}}\left(\mathrm{t}_{0}\right)-\mathrm{V}_{1}\right] \frac{\sin \omega_{1} \mathrm{t}}{\omega_{1} \mathrm{~L}_{3}}
\end{aligned}
$$

Where:

$$
\begin{aligned}
& \omega_{1}=\frac{1}{\sqrt{\mathrm{L}_{3} \mathrm{C}_{1}}} \\
& \text { When } \mathrm{D}_{3} \text { stops conducting and this mode comes to }
\end{aligned}
$$
an end.

Mode 2: The initial conditions on $\mathrm{L}_{3}, \mathrm{~L}_{2}$ and $\mathrm{C}_{1}$ are, $\mathrm{i}_{\mathrm{L}_{3}}$ $\left(t_{1}\right), i_{L_{2}}\left(t_{1}\right)+I$ and $V_{C_{1}}$ respectively, attained at the end of. Mode 1.The expressions are Eq. 11-13:

$$
\begin{aligned}
& \mathrm{v}_{\mathrm{C}_{1}}(\mathrm{t})=-\mathrm{V}_{\mathrm{C}_{1}}\left(\mathrm{t}_{1}\right)\left[1-\cos \omega_{2} \mathrm{t}\right] \\
& +\frac{\mathrm{i}_{\mathrm{L}_{3}}\left(\mathrm{t}_{1}\right)}{\omega_{2} \mathrm{C}_{1}} \sin \omega_{2} \mathrm{t}-\mathrm{V}_{\mathrm{C}_{1}}\left(\mathrm{t}_{0}\right) \\
& \mathrm{i}_{\mathrm{L}_{3}}(\mathrm{t})=\frac{\mathrm{V}_{\mathrm{C}_{1}}\left(\mathrm{t}_{1}\right)}{\omega_{2}\left(\mathrm{~L}_{1}+\mathrm{L}_{3}\right)} \sin \omega_{2} \mathrm{t}+\mathrm{i}_{\mathrm{L}_{3}}\left(\mathrm{t}_{1}\right) \cos \omega_{2} \mathrm{t} \\
& \mathrm{i}_{\mathrm{L}_{2}}(\mathrm{t})=\frac{\mathrm{V}_{\mathrm{C}_{1}}\left(\mathrm{t}_{1}\right)}{\omega_{2}\left(\mathrm{~L}_{2}+\mathrm{L}_{3}\right)} \sin \omega_{2} \mathrm{t}+\mathrm{i}_{\mathrm{L}_{3}}\left(\mathrm{t}_{1}\right) \cos \omega_{2} \mathrm{t}+\mathrm{I}_{1}
\end{aligned}
$$

Where:

$$
\omega_{2}=\frac{1}{\left(\sqrt{\left.L_{2}+L_{3}\right) C_{1}}\right.}
$$

This mode comes to an end when $\mathrm{V}_{\mathrm{C} 1}$ reaches zero at $\mathrm{t}_{2}$.

Mode 3: The initial conditions on $\mathrm{i}_{\mathrm{L}_{2}}, \mathrm{i}_{\mathrm{L}_{3}}$ and $\mathrm{V}_{\mathrm{C}_{1}}$ for this mode $i_{L_{2}}\left(t_{2}\right), i_{L_{3}}\left(t_{2}\right)$ are zero. The expression For $i_{L 3}$ is Eq. 14-16:

$$
\mathrm{i}_{\mathrm{L}_{3}}(\mathrm{t})=-\frac{\mathrm{V}_{\mathrm{S}} \mathrm{L}_{2}}{\left(\mathrm{~L}_{1} \mathrm{~L}_{2}+\mathrm{L}_{2} \mathrm{~L}_{3}+\mathrm{L}_{3} \mathrm{~L}_{1}\right)} \mathrm{t}+\mathrm{I}_{\mathrm{L}_{3}}\left(\mathrm{t}_{2}\right)
$$

This mode comes to an end at $t_{3}$ when $i_{L_{3}}$ reaches zero at $\mathrm{t}_{3}$.

Mode 4: In this mode current buildup in L1 and L2 and Vout (t) are governed by the Eq. as follows. 
$\mathrm{i}_{\mathrm{L}_{1}}(\mathrm{t})=\mathrm{i}_{\mathrm{L}_{2}}(\mathrm{t})=\frac{\mathrm{V}_{\mathrm{S}}}{\mathrm{L}_{1}+\mathrm{L}_{2}} \mathrm{t}+\mathrm{I}_{1}$

$$
\mathrm{V}_{\text {out }}(\mathrm{t})=\mathrm{V}_{1} \mathrm{e}^{\frac{1}{\mathrm{RC}_{2}}}
$$

This mode comes to an end when $S_{1}$ is turned off at zero voltage at $4_{\mathrm{t}}$.

Mode 5: This mode begins with the turn off of $S_{1}$ at zero voltage at $\mathrm{t}_{4}$. The expressions are Eq. 17-20:

$$
\begin{aligned}
& V_{C_{1}}(t)=V_{2}\left(1-\cos \omega_{3} t\right)+\frac{I_{2}}{\omega_{2} C_{1}} \sin \omega_{3} t \\
& I_{L_{2}}(t)=\frac{L_{2}}{\left(L_{2}+L_{3}\right)}\left[V_{2} C_{1} \sin \omega_{3} t-I_{2}\left(1-\cos \omega_{3} t\right)\right]+I_{2} \\
& I_{L_{3}}(t)=\frac{L_{2}}{\left(L_{2}+L_{3}\right)}\left[-V_{2} C_{1} \omega_{3} \sin \omega_{3} t+I_{2}\left(1-\cos \omega_{3} t\right)\right]
\end{aligned}
$$

Mode 6: In this mode $i_{L_{3}}$ reduces to zero. This mode comes to an end at $t_{6}$ when $i_{L_{3}}$ becomes zero. The expression for $\mathrm{i}_{\mathrm{L}_{3}}$ and $\mathrm{V}_{\mathrm{C}_{1}}$ for these mode is.

$$
\begin{aligned}
& \mathrm{i}_{\mathrm{L}_{3}}=\frac{\mathrm{V}_{\mathrm{C}_{1}}\left(\mathrm{t}_{5}\right)-\mathrm{V}_{2}}{\mathrm{~L}_{3} \omega_{1}} \sin \omega_{1} \mathrm{t}+\mathrm{i}_{\mathrm{L}_{3}}\left(\mathrm{t}_{5}\right) \cos \omega_{1} \mathrm{t} \\
& \mathrm{V}_{\mathrm{C}_{1}}(\mathrm{t})=\left[\mathrm{V}_{\mathrm{C}_{1}}\left(\mathrm{t}_{5}\right)-\mathrm{V}_{2}\right]\left[\cos \omega_{1} \mathrm{t}-1\right] \frac{\mathrm{i}_{\mathrm{L}_{3}}\left(\mathrm{t}_{5}\right)}{\omega_{1} \mathrm{C}_{1}} \sin \omega_{1} \mathrm{t}
\end{aligned}
$$

Mode 7: In this mode $i_{L_{2}}, i_{L_{2}}$ are zero. This mode comes to an end at $t_{7}$ when $S_{1}$ is turned on at zero current. This is the normal mode of the boost converter. The expressions are Eq. 21-22:

$$
\begin{aligned}
& V_{\text {out }}(t)=e^{-\alpha t}\left[A \sin \omega_{4} t+B \sin \omega_{4} t\right]+V_{S} \\
& i_{L_{1}}(t) \frac{\mid V_{\text {out }}(t)}{R}+e^{-\alpha t}\left[\left(-B C_{2}+A_{2} \omega_{4} t\right) \cos \omega_{4} t\right. \\
& \left.-\left(A_{2}+B C_{2} \omega_{4}\right) \sin \omega_{4} t\right]
\end{aligned}
$$

Where:

$$
\begin{aligned}
& \alpha=\frac{1}{2 \mathrm{RC}_{2}}, \omega_{4}=\frac{1}{\sqrt{\mathrm{L}_{1} \mathrm{C}_{2}}} \\
& \mathrm{~A}=\frac{\mathrm{I}_{2}}{\omega_{4} \mathrm{C}_{2}}-\frac{\mathrm{V}_{2}}{\mathrm{R} \omega_{4} \mathrm{C}_{2}}+\frac{\alpha\left(\mathrm{V}_{2}-\mathrm{V}_{5}\right)}{\omega_{4}}
\end{aligned}
$$

$\mathrm{B}=\mathrm{V}_{2^{-}}-\mathrm{V}_{\mathrm{S}}$

\section{MATERIALS AND METHODS}

Design of PI controller: A PI Controller (proportionalintegral controller) is a feedback controller which drives the plant to be controlled with a weighted sum of the error (difference between the output and desired setpoint) and the integral of that value. PI controller is mainly used to improve the performance of the system under disturbances. The dynamic performance of the PI controller can be improved by giving feedback to the converter to overcome the disturbances. A proportionalintegral controller employed with a feedback loop can take the place of manual adjustment in DC-DC converter and act much more quickly than is possible. Consider the DC-DC converter as "a process," The DCDC converter includes the converter itself, plus the DC power supply. To automate the control process, the "feedback loop" is closed, producing an error signal (+ or $-)$. The PI controller acts upon the error with parallel proportional and integral responses in an attempt to drive the error to zero. When $\alpha \mathrm{V}$ out equals $\mathrm{V}$ set, then the error is zero. It can be used with the op-amp implementation of the controller. A proportional-integral controller (i.e., PI) employed with a feedback loop can take the place of manual adjustment in DC-DC converter and act much more quickly than is possible "by hand." Consider the DC-DC converter as "a process,"

The controller output is given by Eq. 22.1-22.3:

$\mathrm{K}_{\mathrm{P}} \Delta+\mathrm{K}_{\mathrm{I}} \int \Delta \mathrm{dt}$

where, $\Delta$ is the error or deviation of actual measured value (PV) from the Set-Point (SP).

$\Delta=\mathrm{SP}-\mathrm{PV}$

A PI controller can be modeled easily in software such as Simulink using a "flow chart" box involving Laplace operators:

$\mathrm{C}=\frac{\mathrm{G}(1+\mathrm{Ts})}{\mathrm{Ts}}$

Where:

$\mathrm{G}=\mathrm{K}_{\mathrm{P}}=$ proportional gain

$\mathrm{G} / \tau=\mathrm{K}_{\mathrm{I}}=$ integral gain 
Setting a value for $G$ is often a tradeoff between decreasing overshoot and increasing settling time.

Design of PI controller for a boost converter: PI control is a traditional linear control method used in industrial applications. The linear PI controller controllers are usually designed for dc-dc converters using standard frequency response techniques and based on the small signal model of the converter. A Bode plot is used in the design to obtain the desired loop gain, crossover frequency and phase margin. The stability of the system is guaranteed by an adequate phase margin. However, linear PID and PI controllers can only be designed for one nominal operating point. A boost converter's small signal model changes when the operating point varies. The poles and a right-half plane zero, as well as the magnitude of the frequency response, are all dependent on the duty cycle.

Therefore, it is difficult for the PID controller to respond well to changes in operating point. The PI controller is designed for the boost converter for operation during a start up transient and steady state respectively. The load current of the proposed converter is given to the PI controller. The time constant of the controller is designed according to the small signal transfer function of the boost converter which is given below. Then the output of the PI controller changes the pulse width of the square wave which changes the firing angle of the MOSFET switch, so the output of the converter is controlled for different load disturbances.

The small signal model of the boost converter is designed based on the average state space averaging techniques, the small signal transfer function of a boost converter is Eq. 22.4:

$$
\frac{\mathrm{Vo}(\mathrm{s})}{\mathrm{D}(\mathrm{s})}=\frac{\mathrm{Vs}}{(1-\mathrm{D})^{2}} \frac{\left(1-\mathrm{s} \frac{\mathrm{L}}{\mathrm{R}(1-\mathrm{D})^{2}}\right)}{1+\mathrm{s} \frac{\mathrm{L}}{\mathrm{R}(1-\mathrm{D})^{2}}+\mathrm{s}^{2} \frac{\mathrm{LC}}{(1-\mathrm{D})^{2}}}
$$

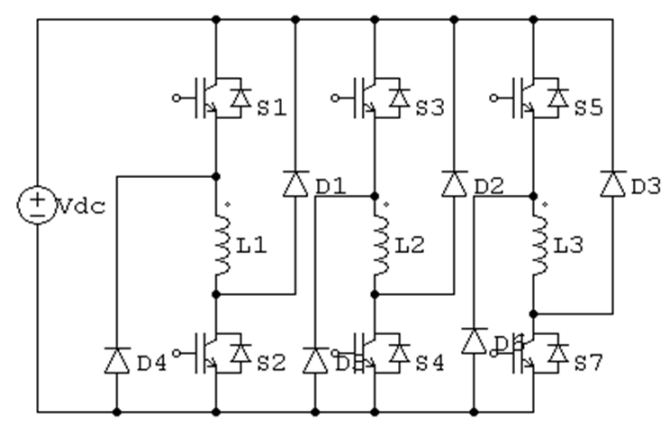

Fig. 4.Unipolar converter with two switches per phase
Design of power Converter: Figure 4 show the unipolar converter with two switches per phase which is a power converter for srm. The regulated output from the soft switched converter is fed to the power converter. The gate signals to the switches controls the speed of srm, getting the PWM signal from the PI controller.

\section{RESULTS AND DISCUSSION}

The proposed soft switched converter is designed and simulated using MATLAB/SIMULINK. Two PI controllers are designed and simulated to regulate the input voltage fed to srm and control the speed of srm. The outputs are clearly shown that the soft switched converter with PI controller regulates the input supply to $300 \mathrm{~V}$ as constant and the power converter with PI controller maintains a constant speed $3000 \mathrm{rpm}$ in a 3 phase $6 / 4$ poles SRM. The outputs are constant for any load and line variations.

Figure 5 shows the input three phase ac supply fed to the rectifier.

Figure 6 shows the regulated output voltage from the softswitched $\mathrm{dc}$ dc converter. The converter is controlled by a PI controller. It is clearly seen that the output voltage is constant for any line variations.

In the speed control method of srm most of the control is done by current, which is called as current controller. The Fig. 7 shows the rotor current, which is feedback to the converter by comparing with the reference current and variable speed from the SRM.

Figure 8 shows the constant speed 3000rpm is maintained in the srm for any load variations.

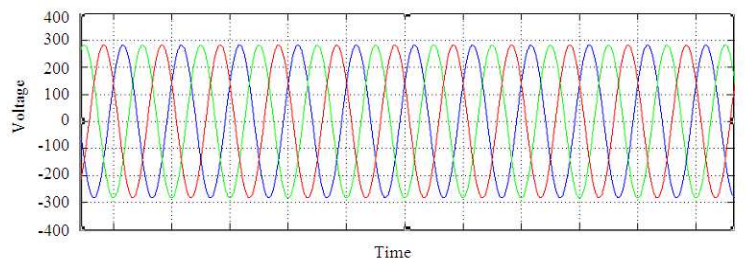

Fig. 5: Input voltage

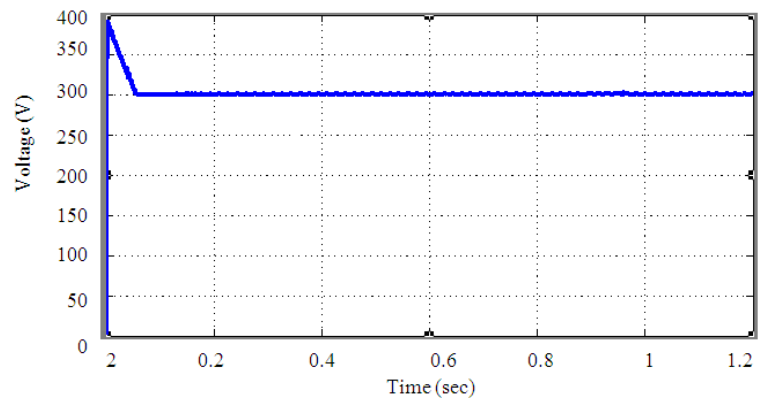

Fig. 6: Regulated output voltage from the proposed Converter 


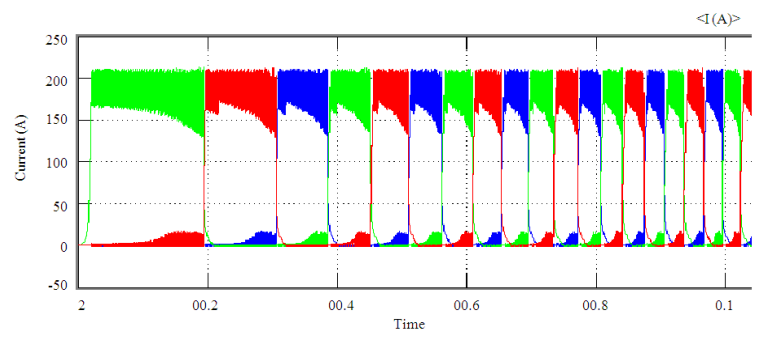

Fig. 7: Output current in the SRM

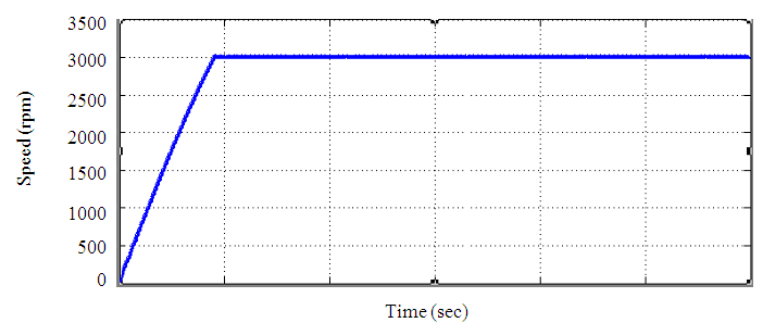

Fig. 8: Speed in the SRM

\section{CONCLUSION}

Thus a soft switching scheme is designed and simulated for SRM to regulate the input voltage to srm and control the speed of srm with a feedback controller. Two PI controllers are used as feedback control. We have simulated the soft switching technique and achieved the low stress and less switching loss in the converter. The linear PI controllers were designed based on frequency response of the boost converter using frequency response technique. The simulated results shows that the only switch used in this converter is switched $\mathrm{ON}$ at zero current and switched OFF at zero voltage. The output voltage is boosted and it is constant at steady state. It reaches the steady state value within several micro seconds for any line variations. It also maintains a constant speed foe any load variation.

\section{REFERENCES}

Guanxu, Z., W. Jixiang., R. Lanjie., A. Jinwoo, 2009 Adaptive PID control for hydraulic pump system based on fuzzy logic. Proceedings of the IEEE 6th Power Electronics and Motion Control Conference, May 17-20, IEEE Xplore Press, Wuhan, pp: 20682071. DOI: 10.1109/IPEMC.2009.5157738
Kumar, R., R.A. Gupta, S. Goyal, S.K. Bishnoi, 2006. Fuzzy tuned PID controller based PFC converterinverter fed SRM drive. Proceedings of the IEEE International Conference on Industrial Technology, Dec. 15-17, IEEE Xplore Press, Mumbai, pp: 2498-2503: DOI: 10.1109/ICIT.2006.372632

Lenin, N.C. and R. Arumugam, 2010. A Novel linear switched reluctance machine: Analysis and Experimental Verification. Am. J. Eng. Applied Sci. 3: $\quad 433-440 . \quad$ DOI: 10.3844/ajeassp.2010.433.440

Li, H and L. Yue, 2009. Speed control of switched reluctance motor by FVSC System. Proceedings of the WRI Global Congress on Intelligent Systems, May 19-21, IEEE Xplore Press, Xiamen, pp: 521525: DOI: $10.1109 /$ GCIS.2009.234

Maruthachalam, S. and N. Palaniswamy, 2011. Determination of flux linkage characteristics and inductance of a submersible switched reluctance motor using software tools. J. Comput. Sci. 7: 179187 DOI: $10.3844 /$ jcssp.2011.179.187

Mianhua, W. 2009. The Fuzzy-PI control of switched reluctance motor based on DTC. Proceedings of the International Conference on Measuring Technology and Mechatronics Automation, Apr. 11-12, IEEE Xplore Press, Zhangjiajie, Hunan, pp: 606-609. DOI: 10.1109/ICMTMA.2009.533

Reis, L.L.N.D., F. Sobreira, A.R.R. Coelhoa O.M. Almeida and J.C.T. Campos et al., 2009. Identification and adaptive speed control for switched reluctance motor using DSP. Proceedings of the Power Electronics Conference, Sep. 27-Oct. 1, IEEE Xplore Press, Bonito-Mato Grosso do Sul, pp: 836-841. DOI: 10.1109/COBEP.2009.5347659

Song, A. Y. Cao and D. Gu, 2010. Study of based fuzzy-PID control for switched reluctance motor. Proceedings of the International Conference on Computer Design and Applications, Jun. 25-27, IEEE Xplore Press, Qinhuangdao, pp: V3-558- V3561 DOI: $10.1109 /$ ICCDA.2010.5541360 